\title{
Influence of the variety on the quality of organic black currant juices
}

\author{
Elena Salina ${ }^{1^{*}}$, Nadezhda Levgerova ${ }^{1}$, and Sergey Knyasev ${ }^{1}$ \\ ${ }^{1}$ All-Russian Research Institute of Fruit Crops Breeding, Orel, 302530, Russia
}

\begin{abstract}
The results of a comparative study of the quality of blackcurrant juices of five varieties of ARSRIFCB breeding suitable for industrial commercial use are presented: Azhurnaya, Orlovskaya Serenada, Orlovsky Vals, Ocharovanye, Chudnoye Mgnovenye. The sensory profiles of juices and their relation to scoring and varietal characteristics were studied. An analysis of the sensory qualities of mono-varietal blackcurrant juices showed that they largely depend on varietal characteristics, such as transparency and thickness, the sensation of acidity and sweetness, and the softness of the taste (absence of harsh acid in the taste). The indicators of the point analysis confirm the results of the descriptor. Sensory analysis data (point and descriptor) showed that preference is given to products with a ruby-red color, typical for blackcurrant juices, bright, not cloudy. Among the studied varieties, of great interest for juice production are the varieties Ocharovanye and Azhurnaya.
\end{abstract}

Black currant (Ribes nigrum L.) is one of the most widespread industrial berry crops in the world, the fruits of which are mainly processed $[1,2]$. Juicing is one of the most popular ways to process fruits and berries. Due to the high content of biologically active substances, the consumption of juices and extracts from black currant is recommended for athletes and people leading an active lifestyle [3, 4]. Directly pressed blackcurrant juice, as a final product entering the market, must have a color, taste and smell characteristic of the berries from which it was produced.

Varietal characteristics of fruit and berry raw materials have a significant impact on the sensory properties of juices produced from them $[1,2]$. For sensory analysis, it is important to select a list of descriptors that adequately describe the product and its properties. Our analysis showed that most studies of blackcurrant juices are related to the study of the influence of various factors on aroma, astringency and stability of sensory properties [4-9]. At the same time, there are very few publications on the sensory profiles of mono-varietal blackcurrant juices. There is no data on descriptor dictionaries describing blackcurrant juices. The All-Russian Research Institute of Breeding of Fruit Crops (VNIISPK) has accumulated a large experimental material on the point organoleptic (sensory) analysis of juices of various varieties of black currant and their biochemical composition, which makes it possible to reveal the influence of the variety on the quality of juices.

The aim of the research was to establish the influence of the variety on the quality of

\footnotetext{
*Corresponding author: salina@,vniispk.ru
} 
organic mono-varietal blackcurrant juices.

The objects of the study were five varieties of black currant, suitable for industrial commercial use: Azhurnaya, Orlovskaya Serenada, Orlovsky Vals, Ocharovanye, Chudnoye Mgnovenye. All varieties of VNIISPK selection are grown on the territory of the Oryol district of the Oryol region. Optimally ripe berries were harvested for three years for processing into juice. To obtain juice, the black currant berries were thoroughly washed to remove external debris from the surface, and crushed with a wooden pestle. Water was added to the resulting pulp in the amount of $15 \%$ by weight of the berries and heated to $50^{\circ} \mathrm{C}$. Then the mass was pressed and filtered through a fabric filter, after which it was pasteurized and sealed in glass bottles. Enzymes were not used because their use in juice processing leads to an increase in astringency and a loss of the fresh aroma of black currant [7]. Sealed juices were stored for 4 months before sensory analysis.

In our study, sensory analysis included visual and taste assessments. The assessment was carried out by experts who took part in closed tastings. Experts - members of the tasting group ( $n=15,3$ - men, 13 - women, at the age of 27-60 years) were selected among the staff of the institute according to the level of taste sensitivity [10]. The members of the tasting group were pre-trained to evaluate blackcurrant juice according to the standards $[11,12]$. There were two specific sessions for basic training in the recognition of taste and aroma and two specific sessions for the formation and agreement of the vocabulary of sensory descriptors. Experts were asked to describe sensory perception during smell and juice tasting in their own words. Inaccurate and rarely used terms have been excluded. Some of the descriptors were taken from literary sources [5-8, 13-15]. The tasting group chairman summarized the results and divided them into visual, olfactory and gustatory term groups. From these data, a list of descriptor terms was selected for further work (Table 1).

Table 1. Groups of descriptors for sensory analysis of black currant juice

\begin{tabular}{|l|l|l|}
\hline \multicolumn{1}{|c|}{ Visual descriptors } & \multicolumn{1}{c|}{ Olfactory descriptors } & \multicolumn{1}{c|}{ Flavor descriptors } \\
\hline Ruby & Currant & Sweet \\
\hline Red & Grassy & Sour \\
\hline Brown & Natural & Tart \\
\hline Dark & Pleasant & Bitter \\
\hline Bright & Foreign smell & Soft \\
\hline Thick & Typical & Empty \\
\hline Turbid & & Foreign taste \\
\hline Typical & & Typical \\
\hline
\end{tabular}

To assess the intensity of the manifestation of the qualities described by the descriptors, a 5-point continuous scale was chosen ( 1 - the feature was not detected, 5 - the feature was expressed intensively). For analysis, 5 juice samples were randomly assigned to 4 blocks. Each sample was presented in triplicate. One block was analyzed in each session, the interval between sessions was 2 - 3 days. Each juice sample $(50 \mathrm{ml})$ was encoded with a three-digit number and presented in a transparent glass. Each participant in the tasting group had a glass of water. Based on the estimates obtained, profillograms of juices were constructed.

The organoleptic point assessment was carried out by a tasting group in a closed tasting on a 5-point scale (5 - excellent quality, 1 - not suitable for consumption). For a more accurate assessment, tenths of a point were indicated. The appearance and taste of the juices were evaluated, and based on the data obtained, an overall tasting score was derived.

All data are expressed in tables as mean \pm standard error (SE). Statistical processing of the data obtained was carried out by conventional methods using standard computer programs Microsoft Excel. The reliability of the results was assessed by Student's t-test at $p \leq 0.05$. The significance of differences between cultivars was assessed using variance and post hoc 
analyzes (Tukey post hoc test).

In appearance, all samples were characterized by a ruby or ruby-red color typical of blackcurrant juice. Brownish tones were noted only in the juice of the Orlovsky Vals variety. On this basis, the variety Orlovsky Vals significantly differed from the varieties Azhurnaya, Orlovskaya Serenada and Chudnoye Mgnovenye, which is confirmed by Tukey's test (Fig. $1)$.

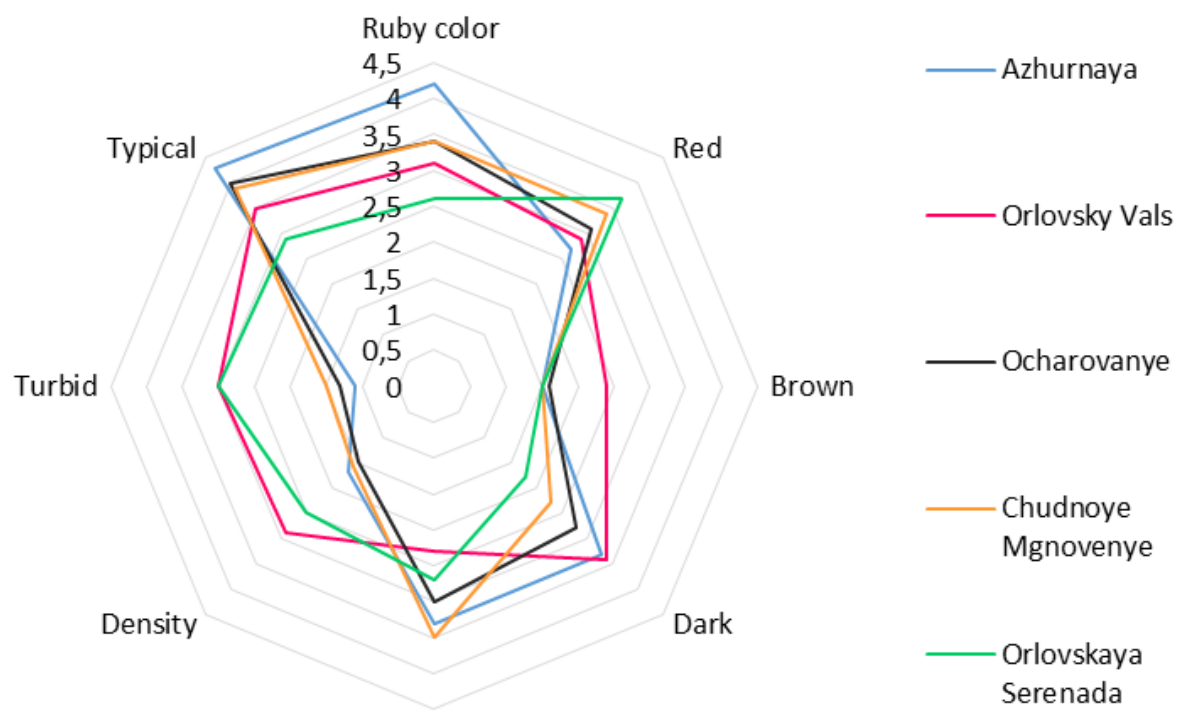

Bright

Fig. 1. Characteristics of the appearance of black currant juices. The statistically significant difference between varieties iconfirmed by the data of analysis of variance and Tukey's test

The juice of the Azhurnaya variety stood out especially: bright, rather intense ruby color, transparent. Of great interest for juice production, along with the Azhurnaya variety, is the Ocharovanye variety, which allows obtaining juice with high marks for its appearance (Fig. 1). The juices of the varieties Orlovsky Vals and Orlovskaya Serenada were thick and opaque, which is evidently explained by the higher content of soluble pectin in them. Moreover, the juice of the Orlovsky Vals variety was one of the darkest (3.4 points), and the juice of the Orlovskaya Serenada variety was the lightest (1.8 points) and the least typical (2.9 points) (Fig. 1).

An important sensory indicator of juice that characterizes its quality and authenticity is taste. Natural blackcurrant juice should have a sweet-sour taste typical of blackcurrant without any off-flavors, which indicate inadequate quality of raw materials and / or violation of the juice production technology. The profillogram (Fig. 2) shows that most of the prototypes were characterized by a mild typical blackcurrant taste without foreign aftertastes. At the same time, the juice of the Orlovsky Vals variety was distinguished by a more sour taste (3.6 points), and of the Ocharovanye and Azhurnaya varieties - the sweetest (3.5 points). Juices of the Azhurnaya and Orlovsky Vals varieties were divided according to the richness of taste.

The lowest palatability was observed in the Chudnoye Mgnovenye juice. It had sharper, but at the same time empty taste, less typicalness compared to other juices and higher astringency. This was the only sample with an unpleasant off-taste (Fig. 2). 


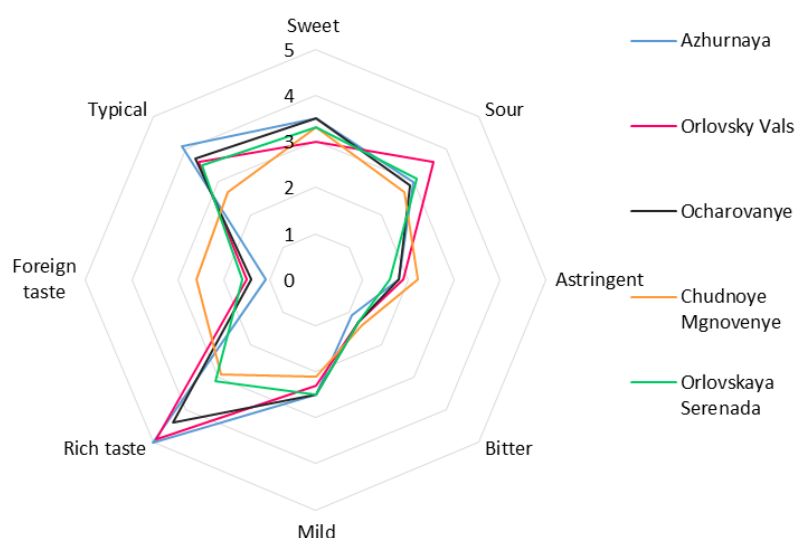

Fig. 2. Characteristics of the taste of blackcurrant juices. The statistically significant difference between varieties confirmed by the data of analysis of variance and Tukey's test

The rest of the varieties practically did not differ in both astringency and bitterness of the juice and were statistically at the same level. Taste indicators often depend on each other. For example, a sweet taste can mask acidity and bitterness. At the same time, the intensity of taste positively correlates with sour taste and negatively - with bitter, which is noted by other researchers [7].

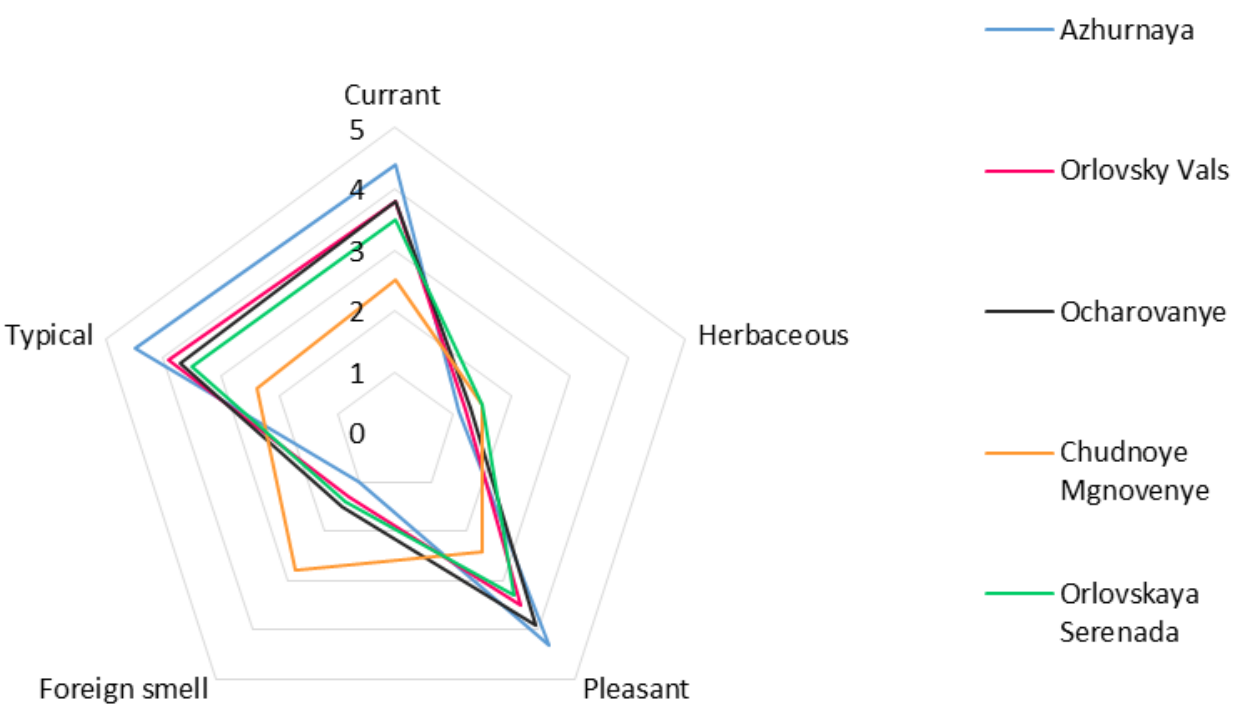

Fig. 3. Characteristics of the aroma of blackcurrant juices. The statistically significant difference between varieties is confirmed by the data of analysis of variance and Tukey's test

Blackcurrant juices have a strong aroma. Juices of the varieties Orlovskaya Serenada, Ocharovanye, Azhurnaya and Orlovsky Vals had a typical black currant aroma, which was estimated at 3.5...4.5 points (above average ... pronounced) (Fig. 3).

Juice of the Chudnoye Mgnovenye variety in its aromatic qualities significantly differed from other juices, having a pleasant, typical currant aroma (2.4 points; 2.4 points; 2.5 points, respectively) and at the same time had a noticeable foreign smell (2.8 points). The aroma in all other samples was rated from 3.5 points in the juice of the Orlovskaya Serenada variety 
to 4.5 points in the juice of the Azhurnaya variety. The latter was distinguished by the most pleasant aroma (4.4 points) without admixture of herbaceous or extraneous tones.

The indicators of the point analysis confirm the results of the descriptor analysis: the varieties with brown tones and more dense in the juice had a lower mark for appearance, and varieties for the taste, the juice of which was distinguished by excessive acid or off-flavor (Fig. 1, 2, table. 2, 3).

Table 2. The results of the point tasting analysis of blackcurrant juices

\begin{tabular}{|l|c|c|c|}
\hline \multirow{2}{*}{ Variety } & \multicolumn{3}{|c|}{ Tasting score, point } \\
\cline { 2 - 4 } & general & appearance & taste \\
\hline Azhurnaya & $4,4 \pm 0,1$ & $4,5 \pm 0,1$ & $4,5 \pm 0,1$ \\
\hline Orlovsky Vals & $4,5 \pm 0,02$ & $4,4 \pm 0,1$ & $4,4 \pm 0,03$ \\
\hline Orlovskaya Serenada & $4,4 \pm 0,1$ & $4,5 \pm 0,1$ & $4,5 \pm 0,1$ \\
\hline Ocharovanye & $4,5 \pm 0,02$ & $4,6 \pm 0,1$ & $4,5 \pm 0,1$ \\
\hline Chudnoe Mgnovenye & $4,5 \pm 0,1$ & $4,4 \pm 0,1$ & $4,4 \pm 0,1$ \\
\hline $\bar{\gamma}$ & $4,5 \pm 0,02$ & $4,5 \pm 0,04$ & $4,5 \pm 0,02$ \\
\hline $\mathrm{v} \%$ & 1,2 & 1,9 & 1,2 \\
\hline$L S D_{05}$ & 0,1 & 0,1 & 0,1 \\
\hline
\end{tabular}

The data of both sensory analyzes showed that preference is given to cloudy blackcurrant juices with a typical bright ruby-red intense color, rich mild sweet taste with minimal astringency, without bitterness and off-flavors (Fig. 2, Tables 2, 3).

Table 3. Relationship (r) between the indices of the point and descriptor analyzes of blackcurrant juices

\begin{tabular}{|l|c||l|c|}
\hline $\begin{array}{c}\text { Juice appearance } \\
\text { (descriptor analysis) }\end{array}$ & $\begin{array}{c}\text { Juice appearance } \\
\text { (point analysis) }\end{array}$ & $\begin{array}{c}\text { Juice taste } \\
\text { (descriptor } \\
\text { analysis) }\end{array}$ & Juice taste (scoring) \\
\hline ruby & 0,12 & sweet & $0,76^{*}$ \\
\hline red & $-0,03$ & sour & $-0,24$ \\
\hline brown & $-0,46$ & tart & $-0,79^{*}$ \\
\hline dark & $-0,08$ & bitter & $-0,58$ \\
\hline bright & 0,10 & soft & $0,92^{*}$ \\
\hline thick & $-0,46$ & rich taste & 0,15 \\
\hline turbid & $-0,39$ & foreign taste & $-0,66$ \\
\hline typical & 0,18 & typical & 0,66 \\
\hline
\end{tabular}

* - significant at the level of probability $\mathrm{P}=0,95$

The study of the sensory qualities of mono-varietal blackcurrant juices showed that they largely depend on varietal characteristics. First, this concerns such indicators as the sensation of acidity and sweetness, the softness of the taste (the absence of harsh acid in the taste), transparency and thickness. Juices of all varieties had a bright saturated color, typical for black currants, from dark ruby to dark red. The exception is the juice of the Orlovsky Vals variety, which had brownish tones in its color. In terms of taste, juices of varieties with a rich taste were distinguished - Ocharovanye and Azhurnaya (sweet) and Orlovsky Vals (sour). Juice of the Chudnoye Mgnovenye variety was distinguished by a sharper, but at the same time empty taste, the least typicality and higher astringency compared to other juices. In terms of its aromatic qualities, the juice of the Azhurnaya variety, which has the most pleasant aroma, stood out. Juice of the Chudnoye Mgnovenye variety significantly differed from other juices by its atypical aroma, which is statistically confirmed. Other varieties were on the same 
level in terms of aromatic characteristics of the juice.

Sensory analysis data (point and descriptor) showed that preference is given to products with a ruby-red color typical for blackcurrant juices, bright, not cloudy.

\section{References}

1. I.A. Gromova, M.S. Voronina, N.V. Makarova, Chem. Plant Raw Mater., 1, 251-257 (2021) https://doi.org/10.14258/jcprm.2021017020

2. E.S. Salina, N.S. Levgerova, I.A. Sidorova, Bulletin of Russian agricultural science, 5, 36-39 (2019) http://doi.org/10.30850/vrsn/2019/5/36-39

3. M.D. Cook, S.D. Myers, S.D. Blacker, M.E.T. Willems, Eur. J. Appl. Physiol. 11, 23572365 (2015) http://doi.org/10.1007/s00421-015-3215-8

4. D. Bonarska-Kujawa, S. Cyboran, R. Zylka, J. Oszmianski, H. Kleszczynska, Biomed Res. Int., 2014, 783059 (2014) http://dx.doi.org/10.1155/2014/783059

5. O. Laaksonen, L. Mäkilä, R. Tahvonen, H. Kallio, B. Yang, Food Chem., 138(4), 24212429 (2013) https://doi.org/10.1016/j.foodchem.2012.12.035

6. J. Milivojevic, A. Slatnar, M. Mikulic-Petkovsek, F. Stampar, M. Nikolic, R. Veberic, J. Agric. Food Chem., 60, 2682-2691 (2012) https://doi.org/10.1021/jf204627m

7. O. Laaksonen, M. Sandell, E. Nordlund, R.L. Heiniö, H.L. Malinen, M. Jaakkola, H. Kallio, Food Chem., 130, 31-41 (2012) https://doi.org/10.1016/j.foodchem.2011.06.048

8. L. Mäkilä, O. Laaksonen, H. Kallio, B. Yang, Food chem., 221, 422-430 (2017) https://doi.org/10.1016/j.foodchem.2016.10.079

9. J. Zheng, B. Yang, V. Ruusunen, O .Laaksonen, R. Tahvonen, J. Hellsten, H. Kallio, J. Agric. Food Chem., 60, 6581-6593 (2012) http://doi.org/10.1021/jf3012739

10.ISO 3972:2011/COR 1:2012. Sensory analysis. Methodology. Method of investigating sensitivity of taste. Technical Corrigendum (2012) https://www.iso.org/standard/62546.html

11. ISO 6658:2017. Sensory analysis. Methodology. General guidance (2017) https://www.iso.org/standard/65519.html

12. ISO 8586:2012. Sensory analysis. General guidelines for the selection, training and monitoring of selected assessors and expert sensory assessors (2014) https://www.iso.org/standard/45352.html

13. A. Naderi, S. Rezaei, A. Moussa, K. Levers, C.P Earnest. Trends Food Sci. Technol.,74, 85-98 (2018) http://doi.org/10.1016/j.tifs.2018.02.013

14. A. Culetu, F. A. Manolache, D. E. Duta, J. Texture Stud., 45, 138-147 (2013) https://doi.org/10.1111/jtxs.12057

15. M. Warmund, M. Kwasniewski, J. Elmore, A. Thomas, K. Adhikari, HortSci., 51, 15611565 (2016) https://doi.org/10.21273/HORTSCI11290-16 